\title{
Nails Drug Delivery: A Review
}

Navneet Kumar Verma ${ }^{1 *}$, Asheesh Kumar Singh ${ }^{1}$, Prem Chand Mall ${ }^{1}$, Vikas Yadav ${ }^{1}$, Rupali Jaiswal ${ }^{1}$, Karunakar Prasad Dwivedi ${ }^{1}$, Akash Kumar Gupta ${ }^{1}$, Satendra Kumar ${ }^{2}$

${ }^{1}$ Buddha Institute of Pharmacy, GIDA, Gorakhpur Affiliated to Dr. A.P.J. Abdul Kalam Technical University, Lucknow, U.P, India

${ }^{2}$ L.N. Pharmacy College, Govindpur, Baitalpur, Deoria, Affiliated to Dr. A.P.J. Abdul Kalam Technical University, Lucknow, U.P, India

DOI: $10.36347 /$ sajp.2020.v09i04.002

| Received: 09.04.2020 | Accepted: 17.04.2020 | Published: 21.04.2020

*Corresponding author: Navneet Kumar Verma

The purpose of this review is to explore the difficulties in penetration of drug across nail plate $\&$ enhancement of bioavailability of antifungal drug. The existing clinical evidence suggests that a key to successful treatment of fungal diseases by topical antifungal product lies in ineffectively overcoming the nail barrier. Nails drug delivery system \&\#40; NDDS\&\#41; is an important delivery system in mammals, during which their nails are highly suffering from the fungal diseases. This review is to explore the difficulties in penetration of drug across nail plate \& enhancement of bioavailability of antifungal drug. NDDS is that the present topical treatments against the fungal infections by topical antifungal product lies in ineffectively overcoming the nail barrier. The clinical evidence suggests that a key to successful treatment of fungal diseases. The absorption of medicine into the nail unit, following topical application to the nail plate, is very desirable to treat nail disorders, like onychomycosis (fungal infections of the nail). Nail permeability is however quite low and limits topical therapy to early/mild disease states. The factors, which affect drug uptake and permeation through the nail plate like solute molecular size, hydrophilicity / hydrophobicity, charge, and thus the character of the vehicle, are then discussed, followed by ways of enhancing drug transport into and thru the nail plate. Finally, drug-containing nail lacquers which, like cosmetic varnish, are brushed onto the nail plates to form a movie and from which drug is released and penetrates into the nail, recent advances and marketed products are reviewed.

Keywords: NDDS, Nail plate, Fungal disease, Antifungal drugs, Nail barrier.

Copyright @ 2020: This is an open-access article distributed under the terms of the Creative Commons Attribution license which permits unrestricted use, distribution, and reproduction in any medium for non-commercial use (NonCommercial, or CC-BY-NC) provided the original author and source are credited.

\section{INTRODUCTION}

The nail is horny structure. Nail plate is responsible for penetration of drug across it. As it is hard enough the penetration becomes difficult, only a fraction of topical drug penetrates across it. Hence the effective therapeutic concentration is not achieved. The nail plate may appear abnormal as a result of decreased glow. It's involvement of nail bed, reduction of blood supply, physical or chemical features of nail bed. As a result variety of diseases occurs. 1 these diseases can be cured by achieving desired therapeutic concentration of drug by nail drug delivery system. Human nails do not have and decorative role, but can also be considered as an alternative pathway for drug. Delivery, especially in nail diseases such as Onychomycosis or psoriasis. These nail diseases are widely spread in the population, particularly among elderly and immune compromised patients. 2Oral therapies are accompanied by systemic side effects and drug interactions, while topical therapies are limited by the low permeation rate through the nail plate. For the successful treatment of nail disease the applied active drug must permeate through the dense keratinized nail plate and reach deeper layers, the nail bed and the nail matrix. Studies conducted on the human skin elucidated its structure, functions, and its permeability for some substances, but very little is known about skin derivate, the nail, and the properties of nail keratin. The purpose of this work is to improve the understanding of physicochemical parameters that influence drug permeation through the nail plate in order to treat not only topical nail diseases but also to consider the possibility to reach systemic circulation and neighboring target sites. The purpose of this review is to explore the difficulties in penetration of drug across nail plate \& enhancement of bioavailability of antifungal drug. The evidence suggests that a key to successful treatment of fungal diseases by topical antifungal product lies in ineffectively overcoming the nail barrier. Current topical treatments have limited therapeutic effectiveness possibly because they cannot sufficiently penetrate in the nail plate to transport a therapeutically sufficient quantity of antifungal drug to 
the target sites to eradicate the protection. Also the analysis of the drug's penetration is a difficult task. The topical therapy of nail diseases, especially of onychomycosis, and to a smaller extent, of nail psoriasis, is desirable to avoid the side effects associated with their systemic therapy, to increase patient compliance and reduce the cost of treatment. Systemic therapy is however the mainstay of treatment due to the poor permeability of the nail plate to topically applied drugs. For effective topical therapy, fungal drug permeation must be enhanced3. This can be achieved by disrupting the nail plate using physical techniques or chemical agents. Alternatively, drug permeation into the intact nail plate may be encouraged, for example, by iontophoresis or by formulating the drug within a vehicle which enables high drug partition out of the vehicle and into the nail plate. The physical techniques (manual and electrical nail abrasion, acid etching, ablation by lasers, microporation, application of low-frequency ultrasound and electric currents) and chemicals (thiols, sulphites, hydrogen peroxide, urea, water, enzymes) that have shown fungal enhancer activity. The human nail can be afflicted by several disease states including paronychia, psoriasis and infections due to bacteria, viruses or fungi. Whilst rarely life threatening, these generate self-consciousness and psychological stress 4 .Approximately $50 \%$ of all problems result from fungal infections, onychomycoses, and the prevalence of these may be as high as $27 \%$ in Europe and $10 \%$ in the United States . There are many treatment regimens, but the most common involves oral dosing with antifungal agents such as terbinafine or itraconazole. Experimental techniques for investigation of the penetration and distribution of chemicals into and through the nail plate demonstrated that it is possible to deliver drugs to the nail following topical application and led to the development of newer more effective topical products and regimens for treatment of onychomycoses and other nail diseases. A novel ultrasoundmediated drug delivery system has been developed for treatment of a nail fungal disorder (onychomycosis) by improving delivery to the nail bed using ultrasound to increase the permeability of the nail.

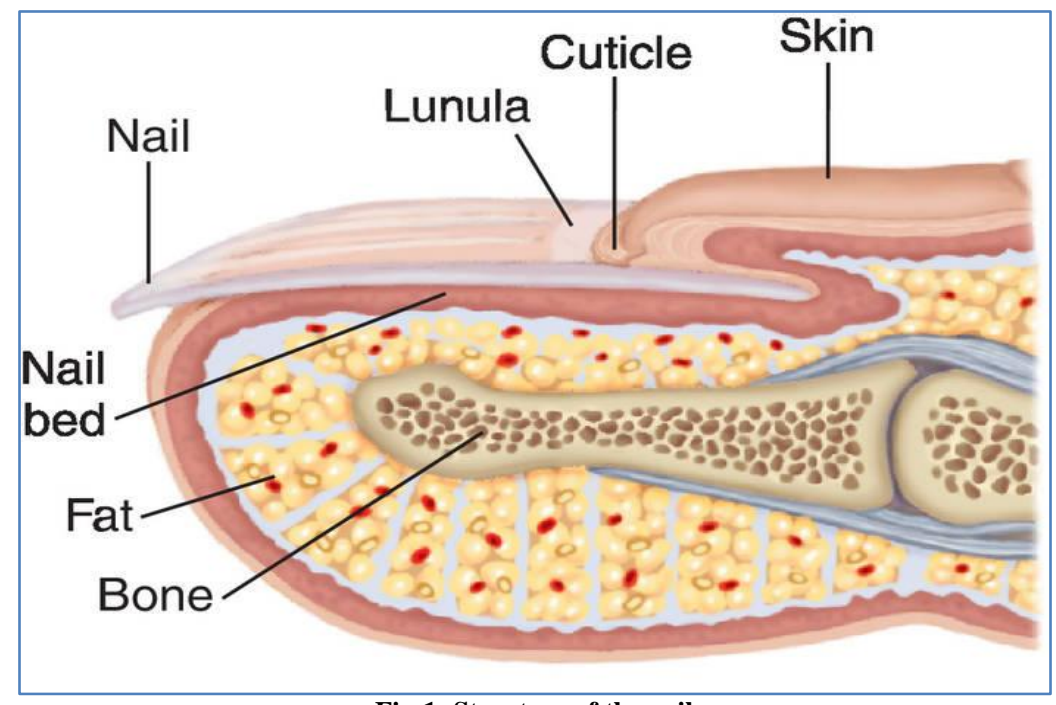

Fig-1: Structure of the nail

The nails are composed of flat, horny scales which form protective covering for the distal of the finger \& toes $[5,6,7]$.Each nail consist of following parts (Figure-1) -

1) A body, the attached uncovering of the nail

2) A free edge, the anterior unattached extension of the body

3) The nail root, the posterior or proximal part of the nail, which lies beneath a fold of the skin.

Most of the body of the nail is pink because it is sufficiently translucent to transmit the colour from the underline vascular tissue. The proximal part of the nail is whitish \& called the lunula because of it has pale moon shape due to the air mixing with the keratin matrix. It has no physiological function.
The fold of skin, which extends around the proximal \& lateral borders of the nail, constitutes the nail fold, \& the skin, which lies beneath the nail, forms the nail bed. The furrow between the nail bed \& nail fold is the nail groove. The nail itself is a hard horny \& consists of several layers of clear, flat cells that contain shrunken \& degenerated nuclei. The striated appearance observed in section cut perpendicular to the surface is produced by the arrangement of the cell in layer.

The bed consist of epithelium and dermis continuous with the epidermis $\&$ dermis if the skin of the nail folds. The epidermis of the nail folds usually has zones characteristic of palmar skin, although the stratum lucidum may thin or absent in some cases. The stratum corneum of the proximal nail fold turns into the nail groove, spreads over the upper surface of the root, and is continuous for a short distance on to the surface 
of the body of the nail as the eponychium.The epithelium of the nail bed corresponds to Malpighian layer of the of skin \& like the later, consists of polygonal prickle cell \& stratum cylindricum resting upon a basement membrane. The epithelium of the posterior part the nail bed, the part that lies beneath the root $\&$ the proximal portion of the body corresponding to the lunula, is thicker than elsewhere $\&$ is called as the matrix because it functions for nail growth. Growth of nail takes place by a transformation of the more superficial cells of the matrix in to true nail cells. In the process the outer, harder layer is pushed forward over the malpighian layer. The nails generally increase in length by about $0.5 \mathrm{~mm} /$ week. Fingernails grow more quickly than toenails \& growth is quickly when the environmental temperature is high. Nail plate is almost completely formed by the $20^{\text {th }}$ week of the fetal life .Under the distal free edges of nail, the epithelium of the nail bed become continuous with the malpighian layer of skin \& the other layers characteristic of the skin thickened and is known as the hyponychium. The dermis of the nail bed differs somewhat from that of ordinary skin. Its connective tissue fibers are arranged partly longitudinal to the long axis of the nail \& partly in a vertical plane extending from the posterior to the nail. Dermal papillae are found beneath the proximal part of the nail root but disappear beneath the distal part of the root, to be replaced by longitudinal dermal ridges which, increase in height as they pass forward, continued to the distal end of the nail bed. Because of the dermal ridges longitudinally, the boundary between the epithelium and connective tissue appears smooth in longitudinal section and irregular and papilla like in cross section. The human nail plate consists of three layers; the dorsal \& intermediate layer derived from the matrix, \& the ventral layer from nail bed. The intermediate layer is three - quarter of the whole nail thickness \& consists of the soft keratin. The upper layer, dorsal, is only a few cell layers thick but consist of hard keratin, with a relatively high sulphur content, mainly in the form of amino acids cysteine, which constitutes $94 \%$ by weight of nail [8]. The upper layer of the nail mainly diffuses into \& through the nail plate. The ventral layer consists of soft hyponychial in which many pathological changes occurs. Thus, in the treatment of these nail diseases; an effective drug concentration in the ventral nail plate would be of great importance. Nail Growth is greatest in childhood and decrease slowly with aging. Due to pressure from posterior nail fold the grows forward instead of upward. Nail growth is also affected by local disturbances in the nail fold or by abnormal keratinization of the nail plate. General or local factor may result in the development in the nail of thicken, ridging, pitting, discoloration, brittleness, splitting, and even separation of nail from its bed (onycholysis). A transverse groove may result from severe illness. The changes in colour for a variety of reasons for instance white spots in the nail plate, which is seen $62 \%$ of normal people, is due to imperfect keratinization with retention of nuclear material.
$\{$ Mospagebreak title=Physiochemical characterization of the human nail

\section{Physiochemical characterization of the human nail}

The plate consists of laminated sheets of keratinized cells. In section, thin lipid seams are seen to separate the layer. This lipids form the original cell membrane coating granules during the plate formation [9]. Apparently no evidence exists concerning fundamental permeation mechanisms \& possible influence of chemical structure on transport across the nail plate. Previous result shown that it is possible to determine nail plate permeability coefficients using standard diffusion cell techniques. Result obtained for water agreed well with the literature data on water transportation through the nail plate. In pursuant studies the techniques have been extended to the permeation of some n-alkanols. These are useful prototype compound with systematically varying oil/water $(\mathrm{o} / \mathrm{w})$ distribution coefficients \& diffusion coefficient. Such structural influence on physiochemical properties, when considered together with relative permeability's, have helped decipher the barrier mechanism of several membranes. Permeation by water \& the n-alcohol through dodecanol has been investigated in specially constructed diffusion chamber. The permeability coefficient of water is $16.5 \times 10^{-3} \mathrm{Cm} \mathrm{h}^{-1} \&$ that for methanol is $5.6 \times 10^{-3} \mathrm{Cm} \mathrm{h}^{-1}$. Ethanol's permeability coefficient measured $5.8 \times 10^{-3}$. Permeability coefficients decreased systematically thereafter to a low value of $0.27 \times 10^{-3} \mathrm{Cm} \mathrm{h}^{-1}$ at n-octanol. The middle chain length alcohol, n-pentanol through n-octanol, have similar permeability coefficient but n-decanol \& n-dodecanol show higher rates of permeation. The data suggest that, as a membrane, the hydrated human nail plates behave like a hydrogel of high ionic strength to the polar \& semi polar alcohols. Declining permeability rates appear linked to decreased partitioning into the complex matrix of the plate as the compounds becomes hydrophobic. The result for n-decanol \& n-dodecanol introduce the possibility that a parallel lipid pathway exists which favors the permeation of these exceedingly hydrophobic species. So the nail become less permeable to the n-alcohols as their hydrophobicity is increased. $\{$ Mospagebreak title $=$ Diseases of the nail $\}$

\section{Diseases of the nail [11-13]}

The nail plate may appear abnormal as result of, a congenital defect, disease of skin with involvement of the nail bed, systematic disease, reduction of blood supply, local trauma, tumors of the nail fold or nail bed, infection of the nail fold, infection of the nail plate.

Leuconychia white spots or lines appears on one or more nails \& grow out spontaneously. Onychomycosis Yellow-brown patches near the lateral border of the nail. Beneath the masses of soft horny debris accumulate $\&$ the nail plate gradually becomes thickened, broken \& irregularly distorted. One or many nails may be affected \& there may be associated 
infection of the skin. Most of the infections are caused by Trichophyton rubrum, T. inerdigitale.

Tinea Unguis, or ringworm of the nails, is characterized by nail thickening, deformity, and eventually results in nail plate loss.

Onychatrophia is an atrophy or wasting away of the nail plate which causes it to lose its luster, become smaller and sometimes shed entirely. Injury or disease may account for this irregularity.

Onychogryposis are claw-type nails are characterized by a thickened nail plate and are often the result of trauma. This type of nail plate will curve inward, pinching the nail bed and sometimes requires surgical intervention to relieve the pain.

Onychorrhexis are brittle nails which often split vertically, peel andlor have vertical ridges. This irregularity can be the result of heredity, the use of strong solvents in the workplace or the home, including household cleaning solutions. Although oil or paraffin treatments will rehydrate the nail plate, one may wish to confer with a physician to rule out disease.

Onychauxis is evidenced by over thickening of the nail plate and may be the result of internal disorders. Leuconychia is evident as white lines or spot in the nail plate and may be caused by tiny bubbles of air that are trapped in the nail plate layers due to trauma. This condition may be hereditary and treatment is required as the spots will grow out with the nail plate.

Beau's lines are nails that are characterized by horizontal lines of darkened cells and linear depressions. The disorder may be caused by trauma, illness, malnutrition or any major metabolic condition, chemotherapy or other damaging event, and is the result of any interruption in the protein formation of the nail plate.

Koilonychia is usually caused through iron deficiency anemia. These nails show raised ridges and are thin and concave.

Melanonychia are vertical pigmented bands, often described as nail 'moles', which usually form in the nail matrix. It could signify a malignant melanoma or lesion. Dark streaks may be a normal occurrence in dark-skinned individuals, and are fairly common.

Psoriasis of the nails is characterized by raw, scaly skin and is sometimes confused with eczema. When it attacks the nail plate, it will leave it pitted, dry and it will often crumble. The plate may separate from the nail bed and may also appear red, orange or brown, with red spots in the lunula.Do not attempt salon treatments on a clients with nail psoriasis.
$\{$ Mospagebreak title $=$ Treatment of nail disorders $\}$

\section{Treatment of nail disorders [14-16]}

The main challenge associated with developing topical treatments for nail disorders is to deliver the active (antifungal) in therapeutically effective concentrations to the site of infection, which is often under the nail. Some research efforts have focused on improving penetration by chemically modifying the nail matrix. However possible means to enhance nail penetration must be explored in greater depth before effective local treatments for fungal nail infections are developed.

\section{Approches of nail drug delivery a) Topical application [6]}

Oral administration of antifungal therapy is inherently associated with GI and systemic side effects. Obviously, topical delivery is the most desired therapy due to relatively less severe side effects and better patient compliance particularly in case of pediatric patients. Unfortunately, there are at least two factors that could limit the accumulation and activity of drugs in the nail on topical application. First, the physicochemical properties of the drug need to be favorable for absorption through nail matrix. The nail matrix is reported to be relatively more permeable to polar compounds than nonpolar compounds. Second, binding of the drug to keratin reduces the availability of the free drug. Antifungal drugs are reported to possess highbinding affinity to keratin.

\section{b) Chemical penetration enhancement [7]}

The common approach for enhancing nail drug delivery has been to use keratolytic and thiolytic agents. These agents are known to increase the permeability of nail matrix by chemical modification of keratin. However, their permeability enhancement potential is limited by the factors like penetrability of enhancer and the duration of its presence in the nail matrix might significantly influence the chemical modification of keratin. Topical monotherapy is considered less efficient in treating nail disorders such asonychomycosis due to poor trans- nail bioavailability of drugs.

\section{c) Physical penetration enhancement $[17,10,18,19]$}

James and coworkers carried out Iontophoresis of prednisolone sodium phosphate across thumb nail and determined the time course of prednisolone in plasma However, there is need for systematic preliminary studies to assess the efficacy and resolve the mechanistic aspects of Iontophoresis across nail. Recently the iontophoretic trans- nail delivery method showed good results in treating nail fungal syndromes. S. Narsimha Murthy and co- workers have studied the effect of Iontophoresis on the permeability of salicylic acid across human nail plate. They conducted diffusion study using Franz diffusion cell incorporated with electrode with it. The results showed drastic increase in 
the permeability of a test penetrant across nail plate as compared with the conventional method of penetration.

\section{ChubTurTM cell}

The cell is composed of donor compartment; nail adapter, receiver chamber and sampling outlet (Fig. 2). In some special cases the electrophoretic assembly is incorporated with the device. The cell depicted below has the capacity to monitor the permeation and deposition of drug from a formulation when applied topically to a nail in vitro. Such a system allows the study, development and optimization of perungual delivery systems in an environment close to those that would occur in vivo.

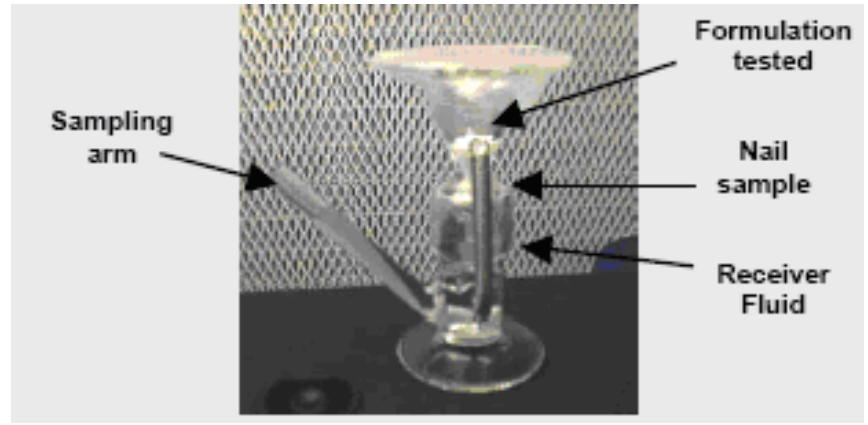

Fig-2: ChubTur TM cell for diffusion study

\section{Recent advances in nails delivery}

Apart from the traditional formulations like nail lacquers, nail varnish, and nail patches recent technologies are introduced in the development of more efficient drug delivery. Here some of the recent technologies are listed which open the new horizons for drug delivery to the human nail.

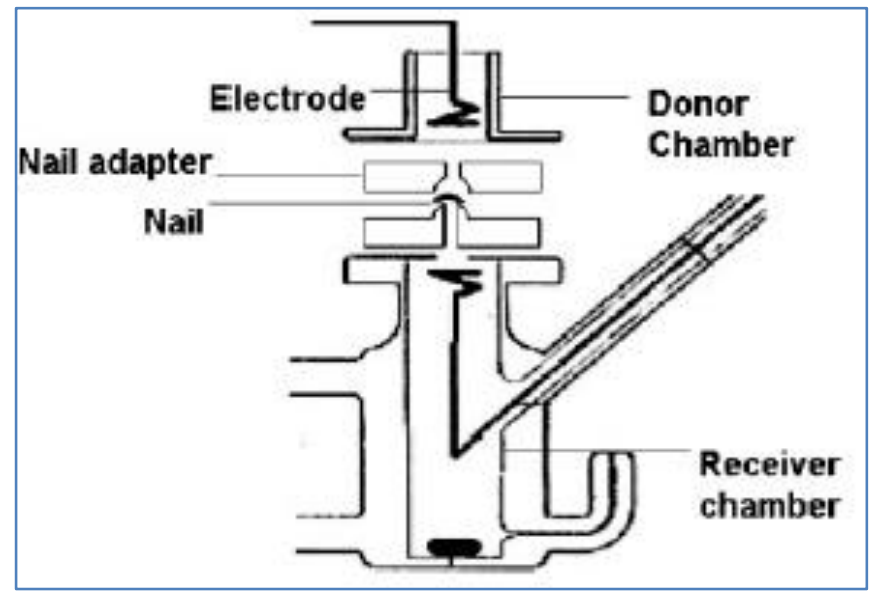

Fig-3: An assembly to study nail penetration by Iontophoresis

\section{a) Electrochemotherapy for Nail disorders}

The goal of this therapy is to develop an active method of drug delivery across the nail plate which in turn is believed to increase the success rate of topical monotherapy and decrease the duration of treatment of nail disorders. Currently, the electrically mediated techniques for drug delivery across the nail plate are investigated. Recently the iontophoretic trans- nail delivery method studied. Iontophoresis was found to enhance the transport of drugs across the nail plate significantly. Similar to transdermal iontophoresis, the predominant mechanisms contributing to enhanced transport of drugs in the case of transnail iontophoresis are electrophoresis and electroosmosis. Iontophoretic permselectivity of the human nail plate and its applicability on the trans- nail delivery of drugs are also under investigation.

\section{b) Mesoscissioning technology}

Mesoscissioning technology creates a microconduit through the skin or nail within a specified depth range. Fully open pathways can be painlessly scized (cut) through the stratum corneum of the skin or through the nail. Microconduits, 300- 500 microns in diameter, are produced within seconds and without sensation. These pathways can be used to deliver drugs across the skin (proof- of- concept in vivo human experiments have shown full anaesthesia occurs within 3 minutes through microconduits compared with $1+$ hour through intact stratum corneum). Such microconduits also permit access for subdermal analyte. Extraction (including blood for glucose testing). In addition, they reduce the skin electrical impedance to less than 1000 ohms for biopotential measurements. In nails, microconduits quickly reduce the painful pressure of subungual hematoma (black toe) and could serve as a 
prophylactic to prevent such pressure build- up in runner's nails.

c) NanoPatch Nail Fungus

NanoPatch Fungus uses AC/DC electrochemistry and targeted drug delivery to actively push antifungal drugs right through the nail cuticle to the actual location of the fungus growth. This would be the first treatment option to directly target nail fungus at its source of growth.

Table-1: Developed formulations for nail disorder [20-23]

\begin{tabular}{|c|c|c|c|c|}
\hline SN & $\begin{array}{l}\text { Name of } \\
\text { product }\end{array}$ & Name of drug & Uses/Indications & $\begin{array}{l}\text { Name } \\
\text { Company }\end{array}$ \\
\hline 1 & $\begin{array}{l}\text { Eco-Nail } \\
\text { nail lacquer }\end{array}$ & $\begin{array}{l}5 \% \text { econazole } \\
+18 \% \text { SEPA } \\
\text { nail lacquer }\end{array}$ & $\begin{array}{l}\text { Promotes the release of econazole from dried } \\
\text { lacquer film, creating a large chemical gradient at } \\
\text { the lacquernail interface, to drive econazole into } \\
\text { the deep nail plate SEPA acts as a percutaneous } \\
\text { penetration enhancer which itself has no effect on } \\
\text { nail and do not penetrate nail. }\end{array}$ & $\begin{array}{l}\text { Macro Chem } \\
\text { Corporation }\end{array}$ \\
\hline 2 & $\begin{array}{l}\text { Loceryl } \\
\text { nail film }\end{array}$ & $\begin{array}{l}\text { Antifungal } \\
\text { drug, } \\
\text { amorolfine }\end{array}$ & $\begin{array}{l}\text { A non-water-soluble film of amorolfine formed on } \\
\text { the nail plate, and this film remains in place for } 1 \\
\text { week. The film contains a high concentration of } \\
\text { amorolfine and forms a depot from which the drug } \\
\text { is delivered and which allows the drug to permeate } \\
\text { the nail plate. }\end{array}$ & $\begin{array}{l}\text { Galderma } \\
\text { Australia Pty Ltd }\end{array}$ \\
\hline 3 & $\begin{array}{l}\text { Umecta nail } \\
\text { Film }\end{array}$ & Urea $40 \%$ & Psoriatic nails, brittle and thick nails, and calluses & $\begin{array}{l}\text { JSJ } \\
\text { Pharmaceuticals }\end{array}$ \\
\hline 4 & $\begin{array}{l}\text { Tazorac } 0.1 \% \\
\text { Gel }\end{array}$ & Tazarotene & Used in the Treatment of Fingernail Psoriasis & Allergan Inc \\
\hline 5 & $\begin{array}{l}\text { Zalain nail } \\
\text { patch }\end{array}$ & $\begin{array}{l}\text { Sertaconazol } \\
\text { Nitrate }\end{array}$ & $\begin{array}{l}\text { Once-a-week nail patch for treatment of } \\
\text { onychomycosis \& onychodystrophy }\end{array}$ & Labtec \\
\hline 6 & $\begin{array}{l}\text { Penlac nail } \\
\text { lacquer }\end{array}$ & $\begin{array}{l}\text { Ciclopirox } \\
\text { topical } \\
\text { solution } \\
\end{array}$ & $\begin{array}{l}\text { a broad-spectrum antifungal medication that also } \\
\text { has antibacterial and anti-inflammatory properties }\end{array}$ & $\begin{array}{l}\text { Dermik } \\
\text { Laboratories Inc. }\end{array}$ \\
\hline
\end{tabular}

\section{CONCLUSION}

Various Nails disorders are very difficult to cure because of their complex structure and unknown mechanism. Few diseases are easily curable.

\section{REFERENCES}

1. Vejnovic I, Simmler, L, Betz G. Investigation of different formulations for drug delivery through the nail plate. Internationa Journal of Pharmaceutics. 2010; 386: 185-194.

2. Gunt HB and Kasting GB. Effect of hydration on the permeation of ketoconazole through human nail plate in vitro. European Journal of sciences. 2007; 32: 254-260.

3. Rubio MC, Ariz IR, Gil J, Benito J, Rezusta A. Potential fungicidal effect of Voriconazole Against Candida spp. International Journal of Antimicrobial Agents. 2005;25:264-267.

4. De Berker DA, André J, Baran R. Nail biology and nail science. International journal of cosmetic science. 2007 Aug;29(4):241-75.

5. Dykyj JD. Anatomy of the nail clin padiatr. Med. surgery. 1989;6(2).

6. Forslind B, Thyresson N. On the structure of the normal nail. Archiv für dermatologische Forschung. 1975 Sep 1;251(3):199-204.
7. Kobayashi Y, Miyamoto M, Sugibayashi K, MORIMOTO Y. Drug permeation through the three layers of the human nail plate. Journal of pharmacy and pharmacology. 1999 Mar;51(3):2718.

8. Hashimoto K, Bernard GG, Nelson R, Lever WF. Journal of Investigative Dermatology. 1966;47: 205-217.

9. Kenneth A, Walters, Gordon L, Flynn, \&John R. Marvel. Physiochemical characterization of the human nail Journal of Pharmacy and Pharmacology.1983; 35:28-33

10. Runne U. The human nail; structure, growth \& pathological changes. Current problem in dermatology.1981; 9:102.

11. Baran R, Dawber RPR, eds. Diseases of the nail \& their management, Oxford: Blackwell scientific publication, Sau P, Brwens disease of the nail bed \& periungnal area arch dermatol.1994; 130: 204.

12. Malhotra GG, Zatz JL. Investigation of nail permeation enhancement by chemical modification using water as a probe. Journal of pharmaceutical sciences. 2002 Feb;91(2):312-23.

13. Sun Y, Liu JC, Kimbleton ES, Wang JC, inventors; Johnson, Johnson Consumer Companies LLC, assignee. Antifungal treatment of nails. United States patent US 5,696,164. 1997 Dec 9. 
14. Soong MH. Transport properties of drugs and model compounds across the human nail.

15. James ME, Graham RM, English J. Percutaneous iontophoresis of prednisolone-a pharmacokinetic study. Clinical and experimental dermatology. 1986 Jan;11(1):54-61.

16. Lawry M. Dermatologic Therapy. 2007; 20,60-67

17. Mertin D, Lippold BC. In- vitro permeability of the human nail and of a keratin membrane from bovine hooves: Influence of the partition coefficient octanol/water and the water solubility of drugs on their permeability and maximum flux. Journal of pharmacy and pharmacology. 1997 Jan;49(1):30-4.

18. Murthy SN, Zhao YL, Hui SW, Sen A. Electroporation and transcutaneous extraction
(ETE) for pharmacokinetic studies of drugs. Journal of controlled release. 2005 Jun 20;105(12):132-41.

19. Nano Patch AC, Inc, www.nanopatchac.co. Accessed May 29, 2009.

20. Path Scientific, LLC, www.pathscientific.com. Accessed May 29, 2009

21. The University of Mississippi, www.pharmacy.olemiss.edu. Accessed May 28, 2009.1

22. Walters KA, Flynn GL, Marvel JR. Penetration of the human nail plate: the effects of vehicle $\mathrm{pH}$ on the permeation of miconazole. Journal of pharmacy and pharmacology. $1985 \mathrm{Jul} ; 37(7): 498-9$. 